\title{
Deve-se retribuir? Gratidão e dívida simbólica na infância
}

\author{
Fernanda Maria Palhares Castro \\ Paula Grazziotin Silveira Rava \\ Tatiana Buchabqui Hoefelmann \\ Maria Adélia Minghelli Pieta \\ Lia Beatriz de Lucca Freitas \\ Universidade Federal do Rio Grande do Sul
}

\begin{abstract}
Resumo
O objetivo deste estudo foi investigar se, para as crianças, haveria obrigação de retribuir um favor, enfocandose as suas justificativas. Realizaram-se entrevistas individuais com 30 crianças, distribuídas em três grupos etários (5-6, 7-8 e 11-12 anos). Utilizou-se uma história na qual um adulto (benfeitor) ajuda uma criança (beneficiário) e investigou-se se o beneficiário deveria retribuir o favor. Os resultados indicaram uma evolução na forma como as crianças concebem a obrigação de retribuir: (a) todas as crianças de 5-6 anos enfocaram consequências para o benfeitor; (b) esse tipo de justificativa diminui com a idade; (c) a retribuição para evitar o juízo alheio negativo foi a explicação mais encontrada entre as crianças a partir dos 7 anos; (d) a retribuição como um bem moral apareceu apenas entre as crianças de 11-12 anos. Este trabalho contribui para a compreensão das diferenças entre gratidão e obrigação e traz subsídios para intervenções educativas.

Palavras-chave: desenvolvimento; moral; gratidão; crianças.
\end{abstract}

\begin{abstract}
Should one return a favor? Gratitude and symbolic debt in childhood. The goal of this study was to investigate whether children feel an obligation to return a favor by focusing on their justifications. Individual interviews were conducted with 30 children from three age-groups (5-6, 7-8, and 11-12 years). We used a story in which an adult (benefactor) helps a child (beneficiary) and investigated whether the beneficiary should return the favor. Results demonstrated an evolution in the form in which children conceive of the obligation to return a favor: (a) all the 5- to 6-year-olds focused on the consequences to the benefactor; (b) this justification diminshed over time; (c) returning a favor to avoid a negative judgment was the most common explanation given by children aged 7 and older; (d) returning a favor as a moral value appeared solely among 11- to 12 -year-olds. This study contributes to the understanding of differences between gratitude and obligation and has implication for educational interventions.
\end{abstract}

Keywords: development; moral; gratitude; children.

$\mathrm{N}$ o universo das trocas entre pessoas - familiares, amigos, vizinhos ou mesmo estranhos - é dada grande importância à reciprocidade ligada às coisas que circulam, sejam presentes, favores ou serviços. Para Simmel (1950), a reciprocidade é tão essencial nas interações humanas que se aprende a experienciar a gratidão durante o processo de socialização.

Na maioria das culturas, a gratidão é admirada e louvada. A ingratidão, pelo contrário, é vista como uma falha moral (De Waal, 2007; McCullough, Kilpatrick, Emmons, \& Larson, 2001). Segundo Comte-Sponville (2007), "agradecer é dar; ser grato é dividir" (p. 146). Aquele que recebe um benefício (presente, favor, ajuda, etc.) sente uma satisfação, uma alegria, e divide essa alegria com o seu benfeitor. Em outras palavras, a pessoa grata reconhece que a sua satisfação se deve, ao menos em parte, ao outro. Para Comte-Sponville (2007), "a ingratidão não é incapacidade de receber, mas incapacidade de retribuir - sob a forma de alegria, sob forma de amor - um pouco da alegria recebida ou sentida" (p. 146).

Pesquisas recentes têm mostrado que expressar gratidão contribui para o bem-estar e para a qualidade de vida das pessoas (e.g., Froh, Sefick, \& Emmons, 2008; Paludo \& Koller, 2006; Sheldon \& Lyubomirsky, 2006). Estudos realizados com adultos indicam que indivíduos que sentem mais gratidão têm níveis mais elevados de felicidade e menores níveis de depressão e stress (McCullough, Tsang, \& Emmons, 2004; Miller, 2006; Watkins, Woodward, Stone, \& Kolts, 2003). Além disso, indivíduos que expressam gratidão, quando comparados àqueles que não o 
fazem, se percebem como sendo mais otimistas e entusiastas, gostam mais de seu trabalho e ajudam mais os outros (e.g., Bartlett \& DeSteno, 2006; Bono, Emmons, \& McCullough, 2004; Froh, Miller, \& Snyder, 2007). Em função desses benefícios, a gratidão deveria ser fomentada desde a infância.

Os estudos sobre o comportamento altruísta dos primatas sugerem que a gratidão faça parte do arcabouço genético dos seres humanos (e.g., Bonnie \& De Waal, 2004; Silk, 2005). Em suas formas mais elementares, pode ser observada também no comportamento de outros animais que vivem em grupo. No entanto, uma vez que "não emerge espontaneamente em recém-nascidos" (Emmons \& Shelton, 2002, p. 468), a gratidão precisa ser cultivada entre crianças e jovens. Em outras palavras, a gratidão não é inata, embora seja possível desenvolvê-la. Todavia, a trajetória do desenvolvimento da gratidão continua uma questão a ser investigada (Froh et al., 2007).

A maioria dos estudos recentes foi realizada com adultos (Froh, 2010; McCullough et al., 2001; Pieta \& Freitas, 2009). Contudo, resultados de pesquisas indicam que a gratidão: (a) contribui para a promoção do bem-estar dos jovens (Froh, 2010; Froh, Kashdan, Ozimkowski, \& Miller, 2009), (b) parece estar relacionada ao sucesso escolar (Bono \& Froh, 2009) e (c) faz parte da vida das crianças (ver também Freitas, Silveira, \& Pieta, 2009a, 2009b; Pieta \& Freitas, 2009).

Pesquisas realizadas com crianças possibilitam não apenas entender a gratidão na infância, mas também compreender como ela se constitui no ser humano. Em outras palavras, estudos sobre o desenvolvimento da gratidão podem nos levar a identificar quais são os tijolos de sua construção (De Waal, 2007): como formas elementares de trocas recíprocas se transformam em um sentimento complexo como a gratidão, o qual envolve conservação no tempo e, portanto, memória capaz de evocar eventos passados, além de capacidade de relacioná-los com o presente (Bonnie \& De Waal, 2004; Godbout, 1997; Piaget, 1965/1977).

Diversos autores (Baumgarten-Tramer, 1938; Bonnie \& De Waal, 2004; Godbout, 1997; Komter, 2004; McConnell, 1993; Piaget, 1965/1977) afirmam que a gratidão implica uma dívida simbólica em relação ao benfeitor e uma obrigação de retribuir o favor, se for possível. A retribuição é um elemento tão presente na gratidão que Westermarck (1908/1928) a definiu como um sentimento retributivo: a retribuição do bem com o bem. Frequentemente sentida como obrigatória, a retribuição tem intrigado os pesquisadores.

De acordo com McConnell (1993), é a natureza gratuita da ação generosa do benfeitor que a torna digna de gratidão. "Isto significa, portanto, que o benefício foi dado livremente (...) e a retribuição não é requerida" (p. 23), sendo estas condições necessárias (embora não suficientes) para que um indivíduo sinta uma dívida de gratidão. Ora, se é necessário que o benefício tenha sido dado livre (sem o intuito de colocar o beneficiário em dívida) e gratuitamente (sem retribuição requerida), por que o beneficiário sente que deve retribuir o benefício recebido? De onde vem essa "força imperativa, uma força que nos compele a retribuir" (Komter, 2004, p. 196)?

Gratidão e obrigação são dois sentimentos distintos (Anderson, 2005; McConnell, 1993; Watkins, Scheer, Ovnicek,
$\&$ Kolts, 2006). Uma diferença comumente apontada é a de que enquanto a gratidão é um sentimento agradável ${ }^{1}$, prazeroso, fonte de bem-estar, a obrigação gera desprazer e mal-estar (McCullough et al., 2001). Todavia, as diferenças entre gratidão e obrigação não estão suficientemente claras na literatura sobre o assunto e ainda necessitam ser investigadas (Anderson, 2005). Uma forma de contribuir para elucidar essa questão é por meio do estudo de como as crianças compreendem a retribuição de um benefício recebido, pois se sabe que o sentimento de obrigatoriedade se desenvolve na infância (Freitas, 2003; La Taille, 2006).

Em seu clássico estudo sobre o desenvolvimento moral, Piaget (1932/1992) constatou que, com a idade, não apenas o respeito, mas também o dever "muda de natureza" (p. 79). Ele verificou que as normas não são inicialmente sentidas como obrigatórias pelas crianças. Por isto, Piaget chamou de anomia a esse período do desenvolvimento moral. Embora desde o nascimento várias regras sejam impostas à criança, ela não entende imediatamente que uma norma não é apenas um costume, isto é, aquilo que se faz, mas é algo que se deve fazer. "Por volta dos 4 anos, a criança começa a conceber que há ações que devem ou não devem $^{2}$ ser realizadas com referência à ideia de que as regras apontam para ações que são boas ou más, certas ou erradas (La Taille, 2006, p. 97). É nesse momento, portanto, que aparece o sentimento de obrigatoriedade.

Segundo Piaget (1932/1992), para que uma norma seja sentida como obrigatória, é necessário que exista um sentimento de respeito entre os indivíduos. Ele chamou de unilateral a primeira forma de respeito que aparece no desenvolvimento do ser humano, o qual tem origem nas relações coativas estabelecidas entre a criança e os mais velhos (pais, professores, etc.). É no interior das relações de coação que nasce a obediência. Quando se considera o estado anterior de anomia, entende-se que essa forma elementar de obrigatoriedade representa uma evolução. Diz-se que se trata de uma evolução, porque é dessa forma que o ser humano deixa de ser escravo de seus impulsos e desejos imediatos. A obediência, contudo, dá origem a uma atitude paradoxal. A criança venera a palavra da autoridade (a regra é sagrada e imutável, aquele que não obedece deve ser castigado, etc.); na prática, porém, ela não a segue. Em síntese, as relações de coação originam uma moral heterônoma, na qual é o outro que regula a conduta do indivíduo.

Os vínculos que a criança estabelece com seus pares é a principal fonte de relações cooperativas, nas quais se estabelece o respeito mútuo. Segundo Piaget (1932/1992), “a peculiaridade da cooperação é justamente conduzir a criança à prática da reciprocidade, portanto, da universalidade moral e da generosidade em suas relações com os parceiros" (p. 48). Uma relação de respeito mútuo não impõe senão a norma de reciprocidade, a qual obriga cada um a se colocar no ponto de vista do outro. Nesse tipo de relação, o indivíduo não pode, ao mesmo tempo, valorizar o seu parceiro e agir de maneira tal que seja desvalorizado por ele. Imaginemos, por exemplo, uma relação entre duas pessoas quaisquer $\mathrm{X}$ e $\mathrm{Y}$ : $\mathrm{X}$ não pode, ao mesmo tempo, prezar Y e lhe roubar, porque, então, este último deixará de estimá-lo e, nesse caso, ou X deixa de prezar Y ou deixa de estimar-se a si mesmo. Isto ocorrerá mesmo que $\mathrm{Y}$ 
ignore que $\mathrm{X}$ foi o autor do roubo e continue estimando-o, visto que “... para aquele que respeita a norma, a obrigação permanece a mesma independentemente da reação do outro" (Piaget, 1965/1977, p. 125). Trata-se da norma de não contradição, no domínio moral, sentida como necessária.

É essa necessidade de coerência interna que garante a conservação dos valores independentemente das pressões do meio social. É assim que, segundo Piaget (1932/1992), as relações de cooperação dão origem à moral autônoma, ou seja, é o indivíduo que se autorregula ao se submeter a normas válidas para qualquer ser humano, qualquer que seja sua idade, grupo cultural, religioso ou étnico. É importante ressaltar que o sentimento de obrigatoriedade gerado nas relações cooperativas não é fonte de desprazer, pois "o sujeito autônomo não é um 'reprimido', mas sim um homem livre, pois livremente convencido de que o respeito mútuo é bom e legítimo" (La Taille, 1992, p. 70).

Em síntese, para Piaget (1932/1992), o sentimento de dever ou obrigatoriedade tem origem em uma relação interindividual de respeito. Há duas formas de respeito - unilateral e mútuo -, os quais têm origem em diferentes tipos de interação social. Existem também duas formas de dever: obediência, derivada das relações de respeito unilateral, e sentimento de dever ou obrigação moral, oriundo das relações de respeito mútuo. Seguindo a tradição kantiana (Freitas, 2002; Queiroz, Ronchi, \& Tokumaru, 2009; Ramozzi-Chiarottino, 2007), Piaget distinguiu aquilo que se faz conforme o dever - heteronomia - e o que se faz por dever - autonomia - e buscou demonstrar que existe um processo evolutivo em direção à segunda. É justamente essa distinção que pode ajudar a compreender a diferença entre a obrigação de retribuir, vivenciada apenas como uma exigência social e que gera desprazer, e a gratidão, a qual engloba uma dívida simbólica e uma obrigação de retribuir, mas é fonte de bem-estar.

Piaget (1932/1992) não desenvolveu estudos empíricos sobre a gratidão. No entanto, segundo ele, a norma de reciprocidade, a qual rege o respeito mútuo, implica também “obrigações positivas" (p. 185) e não apenas deveres negativos como, por exemplo, não mentir e não roubar, os quais ele investigou. Piaget (1954) também sustentou a hipótese de que a gratidão se desenvolveria na infância, abrindo caminhos para este tipo de estudo.

Dentre os estudos empíricos sobre o desenvolvimento da gratidão na infância (ver Freitas et al., 2009a, 2009b; Pieta \& Freitas, 2009), não se encontrou nenhum que abordasse a obrigação de retribuir um favor. Assim, realizou-se uma pesquisa cujo objetivo foi investigar se, para as crianças, haveria obrigação de retribuir um favor. Neste artigo, analisam-se as razões pelas quais, segundo as crianças, se deve ou não retribuir.

\section{Método}

\section{Participantes}

Neste estudo, participaram 30 crianças, distribuídas igualmente em três grupos etários: Grupo $1-5$ e 6 anos, Grupo $2-7$ e 8 anos, e Grupo 3 - 11 e 12 anos. Cada grupo foi constituído pelo mesmo número de meninos e meninas, sendo todos alunos de uma escola ou uma creche, ambas públicas, da cidade de Porto Alegre. A direção de cada instituição escolar assinou um documento autorizando a realização da pesquisa e os pais ou responsáveis legais de todos os participantes assinaram um termo de consentimento livre e esclarecido. Os critérios de inclusão na amostra foram: (a) idade da criança e (b) assinatura do termo de consentimento livre e esclarecido por seus pais ou responsáveis legais.

\section{Instrumento e procedimentos}

Inicialmente, os pesquisadores realizaram um período de familiarização com as crianças nas instituições escolares. As crianças foram convidadas a participar da pesquisa. Foi-lhes assegurado o direito de participar ou não e de desistir de sua participação a qualquer momento. Realizaram-se entrevistas individuais com as crianças de acordo com o método clínico (Delval, 2002; Piaget, 1926/s.d., 1932/1992) dentro do seu ambiente escolar. Utilizou-se como instrumento uma história sobre uma situação hipotética na qual um adulto (benfeitor) presta um favor a uma criança (beneficiário). O benfeitor sempre tinha o mesmo sexo da criança entrevistada. Realizou-se um estudo piloto, por meio do qual foi possível adaptar o texto da história à linguagem das crianças. A história contada para os participantes foi a seguinte: - Ângelo(a) tinha uma gatinha. Um dia ela desapareceu. Tia Ana, que estava fazendo um bolo, disse: "Não tem problema. Eu te ajudo a procurar tua gatinha". Ângelo(a) e tia Ana ficaram muito tempo procurando. No fim do dia, encontraram a gatinha. Tia Ana teve que jogar a massa do bolo fora e começar tudo de novo.

Inicialmente, solicitava-se à criança que recontasse a história, a fim de verificar se ela a havia compreendido. A seguir, iniciava-se a entrevista clínica, a partir das seguintes perguntas básicas: (a) Como Ângelo(a) se sentiu? Por quê?; (b) Ele(a) sentiu mais alguma coisa?; (c) Ele(a) sentiu alguma coisa pela tia Ana? Por quê? e (d) Ângelo(a) deve ajudar a tia Ana a fazer o bolo ou não? Por quê?

As entrevistas foram gravadas e posteriormente transcritas. Em função dos objetivos estabelecidos, neste artigo, analisaramse apenas as respostas das crianças à pergunta "Ângelo(a) deve ajudar a tia Ana a fazer o bolo ou não?" e suas justificativas. A análise dos dados seguiu os passos sugeridos por Delval (2002). Em primeiro lugar, todas as entrevistas foram lidas na íntegra e buscou-se identificar tipos de respostas às questões enfocadas, construindo-se, assim, categorias provisórias de análise. Em segundo lugar, releram-se todos os protocolos, sendo que, desta vez, procurou-se classificar as respostas dos participantes de acordo com essas categorias iniciais. Em terceiro lugar, foram definidas as categorias para as respostas e justificativas das crianças. Estabelecidas as categorias de análise, dois juízes leram independentemente todos os protocolos e classificaram as respostas e justificativas, inserindo os dados em uma planilha SPSS for Windows. Em caso de diferenças (apenas em uma resposta e uma justificativa), cada juiz apresentou seu ponto de vista e chegou-se a um acordo. Finalmente, levantou-se a frequência dos diferentes tipos de resposta nos grupos etários previamente definidos. 


\section{Resultados e discussão}

Três tipos de respostas foram encontrados à pergunta “Ângelo(a) deve ajudar a tia Ana a fazer o bolo?": (a) deve; (b) não deve e (c) pode. A Figura 1 mostra o número de respostas encontrado em cada uma destas categorias, nos diferentes grupos etários.
A maioria dos participantes $(76,7 \%)$ considerou que Ângelo(a) deve ajudar a tia Ana a fazer o bolo. Este foi o tipo de resposta predominante em todos os grupos etários. Para um menor número de crianças $(20 \%)$, ele(a) pode ajudar, se quiser. Esta resposta foi encontrada em todos os grupos. Apenas um participante do Grupo 1 respondeu que Ângelo(a) não deve ajudar a tia Ana a fazer o bolo, mas não justificou sua resposta,

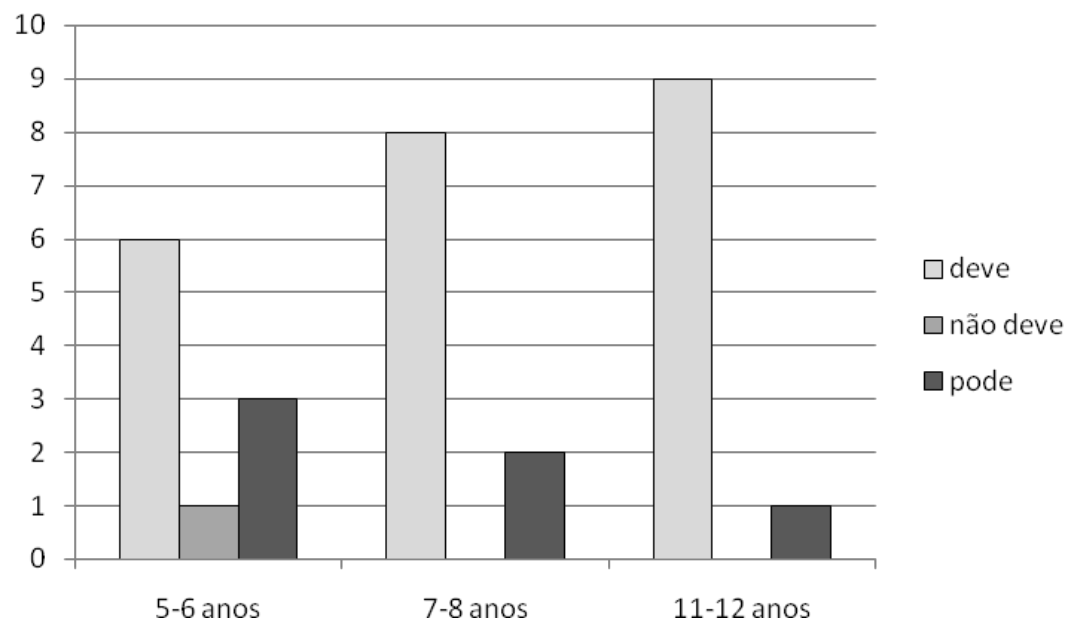

Figura 1. Frequência das respostas dos participantes, por grupo etário, quanto ao dever de ajudar o benfeitor.

dizendo simplesmente "porque não" (Bas, F, 5;2) ${ }^{3}$. Desta forma, ficou-se sem saber por que essa seria uma ação proibida ou reprovável. Somente estudos futuros poderão dizer se essa é uma resposta singular ou se é comum a outras crianças.

Analisaram-se, a seguir, as justificativas apresentadas pelos participantes. As explicações das crianças que disseram que Ângelo(a) deve ajudar a tia Ana a fazer o bolo foram classificadas em três categorias.

Consequência material ou psicológica. Neste tipo de justificativa, não está presente qualquer elemento normativo seja de autoridade seja de reciprocidade. O vínculo afetivo com o outro ou o interesse pelo objeto (o bolo) parecem ser suficientes para justificar a ação benevolente do beneficiário, no caso, ajudar à tia Ana. A criança atém-se às consequências - materiais ou psicológicas - que a falta de ajuda acarretaria ao benfeitor. Se Ângelo(a) não ajudasse, retardaria o processo de preparar o bolo ou a tia Ana sofreria algum dano (ela ficaria triste, furiosa, cansada, etc.). "Pesquisador: Tu achas que o Ângelo deve ajudar a tia a fazer o bolo? Entrevista: Aham ... Pra ela não ficar cansada ... Pesquisador: Por quê? Entrevistado: Pra não demorar a fazer o bolo" (Aug, M, 5;3) ${ }^{4}$. "Deve. Porque a tia Ana não pode fazer tudo sozinha... Se não ajudar, a tia vai ficar furiosa" (Jem, F, 5;5).

A retribuição é uma obrigação. Ajudar à tia Ana é uma forma de retribuição, de agradecimento, à sua ação benevolente. A retribuição é sentida como obrigatória por parte do(a) beneficiário(a) e visa evitar que os outros o(a) julguem mal ou reparar o dano causado. Não retribuir traria um prejuízo para o(a) beneficiário(a), pois ele(a) seria considerado(a) mau (má), mal-agradecido(a), mal-educado(a), egoísta, ingrato(a), preguiçoso(a), etc.

Entrevistado: Deve retribuir o favor. Pesquisador: E se ela não ajudar o que você ia achar dela? Entrevistado: Que ela foi egoísta com a amizade, porque a tia dela foi muito amiga dela ajudando a procurar a gatinha, deixou o bolo de lado, deixou ele ficar queimado, só pra ajudar ela. Então ela devia ajudar no bolo. Porque foi por causa que ela não cuidou bem da gatinha que o bolo ficou queimado, então ela tem que ajudar. (Baq, F, 8;8)

Entrevistado: (...) deve ajudar. Pesquisador: Se o Ângelo não ajudasse a tia Ana a fazer o bolo, o que você ia achar do Ângelo? Entrevistado: Ele não seria um menino educado se não ajudasse. (Lik, M, 8;3)

A retribuição é um bem moral. Ajudar à tia Ana é uma forma de retribuição. A retribuição é sentida como obrigatória. No entanto, este sentimento de obrigação não decorre de uma exigência social imposta. Não é apenas por causa do juízo alheio que o beneficiário deve retribuir. A retribuição é um valor: é bom, é justo retribuir. Retribuir a benesse recebida faz a pessoa sentir-se bem. Retribuir é uma forma de expressar gratidão.

Porque seria um sentimento de justiça, né? Ela ajudou ele a fazer uma coisa e ela ajudar ele a fazer ia recuperar uma coisa por causa dele, por causa da gatinha dele. Só que se fosse da tia 
dele e ela tivesse perdido tempo procurando, ia ser um benefício dela. Já que o benefício foi pra ele, não foi nada dela, e na real ela teve um prejuízo por ter que colocar, fazer tudo de novo, acho que ele tinha que ajudar a recuperar tempo, pra demonstrar que ele tava grato pelo que ela fez. (Pan, M, 12;5)

Acho que ela deve também ajudar a refazer o bolo. Como forma de agradecimento. Se eu ajudei a procurar tua gatinha eu vou ter que ajudar a fazer o bolo, porque tu deixou de fazer o bolo pra ir me ajudar então eu tenho que ajudar. Não é que tenha que ajudar assim, mas é bom ajudar ela... Pra ela se sentir também como ela se sentiu. Pra ela se sentir feliz. (Lap, F, 12;3)

Claro, ela ajudou ele a procurar. Não é que ele tenha que retribuir a boa ação porque ele é obrigado, mas pra ele ficar bem assim, mentalmente, ele tinha que fazer, ajudar porque ela perdeu de fazer um bolo, custos e coisas, pra achar o gatinho dele. Ele devia retribuir também. (Jur, M, 12;8)

Analisaram-se também as justificativas das crianças que disseram que Ângelo(a) pode ajudar tia Ana a fazer o bolo. Para essas crianças, a retribuição não é ou não deve ser uma obrigação, mas depende apenas de uma decisão pessoal.

Entrevistado: (...) ela viu que ela tava um pouco triste porque tinha que fazer tudo de novo a massa do bolo sozinha e aí ela ajudou ela a fazer. Pesquisador: Por que ela ia ajudar a tia Ana a fazer o bolo? Entrevistado: Por causa que a tia Ana ajudou ela também. Pesquisador: E o que tu ias pensar da Ângela se ela não ajudasse a tia Ana? Entrevistado: Não sei. Pesquisador: Pode não ajudar? Entrevistado: Pode, se não quiser pode. Pesquisador: E aí fica tudo bem ou tem algum problema? Entrevistado: Fica tudo bem. (Lab, F, 5;4)

Entrevistado: Porque se ela ajudou ele a procurar a gatinha dele, acho que ele podia ajudar ela. Pesquisador: E se ele não ajudar? Entrevistado: Aí eu não sei o que vai acontecer. Pes- quisador: O que tu achas? Entrevistado: (...) Porque ela fez o bolo e não brigou com ele. Se ela brigasse com ele, ele tinha que fazer mesmo o bolo. Mas como ela não brigou, ele não precisa fazer. Pesquisador: Tu achas que ele não precisa fazer? Entrevistado: Acho que tá bem se ele não fizer. (Meb, M, 7;11)

Entrevistado: Acho que sim porque da mesma forma que a tia Ana deixou de fazer o que ela gostava pra ajudar a sobrinha, ela poderia pegar e ajudar também a tia dela. Pesquisador: Ela poderia ou ela deve? Entrevistado: Acho que poderia. Acho que não é obrigada a fazer uma coisa que talvez ela não queira. Pesquisador: Mas por que ela faria? Entrevistado: Também pra no caso talvez agradecer a tia pelo que ela fez ajudando a procurar a gata. Pesquisador: E se ela não fizesse também estaria bem? Entrevistado: Talvez ajudando a fazer o bolo seria a forma de ela pegar e aí dizer obrigado pra tia dela seria fazer o bolo, mas ela não seria obrigada a fazer isso porque talvez sendo obrigada ela não ajudasse tão bem. (Ces, F, 12;4)

A Figura 2 apresenta o número de respostas encontrado em cada uma dessas categorias nos diferentes grupos etários.

Observa-se na Figura 2 que todas as justificativas das crianças de 5-6 anos que disseram que Ângelo(a) deve ajudar a tia Ana foram classificadas na categoria 1 - consequência material ou psicológica. Evitar um prejuízo material ou psicológico para o benfeitor é a razão pela qual se deve ajudá-lo. Pode-se verificar a necessidade de evitar o prejuízo material nas palavras de Aug (M, 5;3), segundo o qual a falta de ajuda implicaria uma demora maior para fazer o bolo. As palavras de Jem (F, 5;5) ilustram o prejuízo psicológico, pois a falta de ajuda por parte de Ângelo(a) poderia deixar a tia furiosa. Parece que, para essas crianças, a retribuição à ação generosa da tia Ana não é o que constitui a razão para ajudá-la a fazer o bolo. Ajudar é certo, porque evita causar danos. Os participantes que deram esse tipo de justificativa não se referiram a qualquer consequência que a falta de ajuda traria ao beneficiário. Embora tenha aparecido também nos

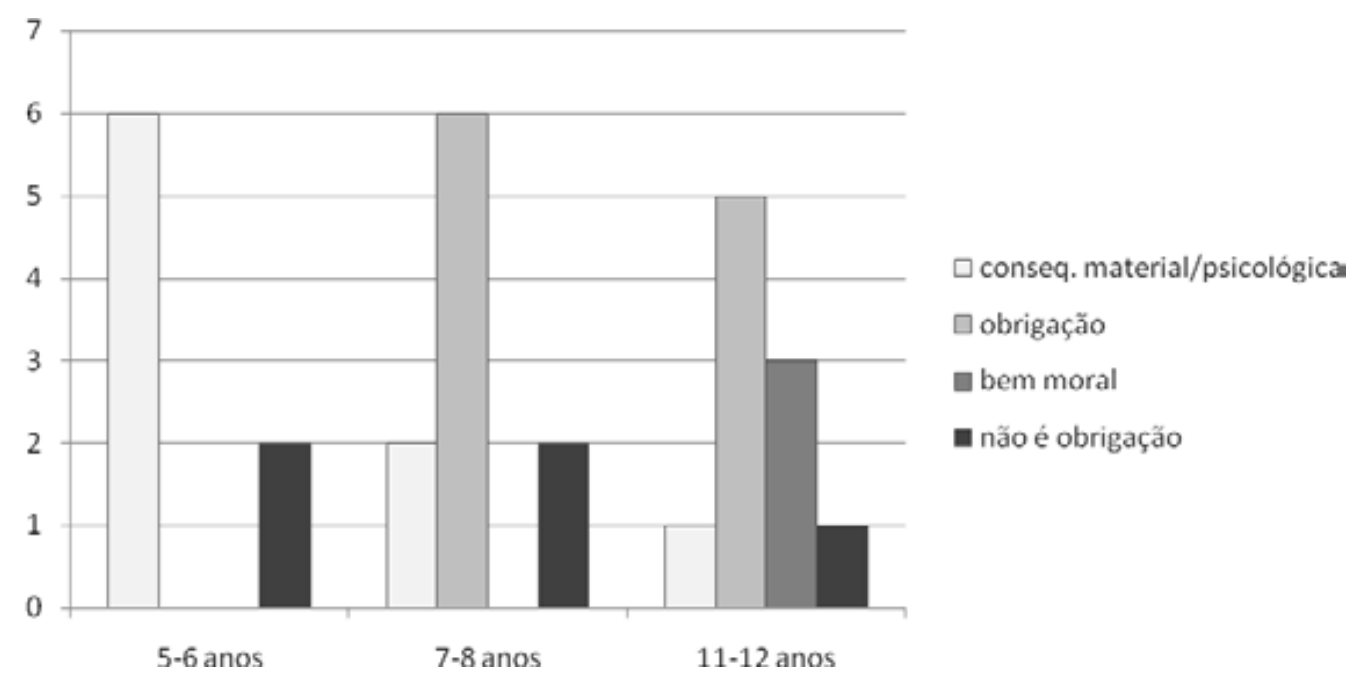

Figura 2. Frequência dos tipos de justificativas dos participantes por grupo etário. 
outros grupos etários, a frequência desse tipo de justificativa diminuiu com a idade.

A retribuição sentida como obrigatória para evitar o juízo alheio negativo foi a justificativa que predominou nas respostas dos participantes dos Grupos 2 e 3. Esta ideia evidencia que é o outro que regula a conduta, sendo esta característica da moral heterônoma. Neste tipo de justificativa, começa a se fazer presente o aspecto virtual que envolve as relações de troca entre os indivíduos (Piaget, 1965/1977). Não retribuir assume um caráter de prejuízo de valores pessoais. $\mathrm{O}$ medo de ser visto pelos outros como egoísta (Baq, F, 8;8) ou mal-educado (Lik, M, 8;3) é o propulsor da atitude benevolente para com o benfeitor prévio.

O terceiro tipo de justificativa - a retribuição como um bem moral - apareceu apenas no Grupo 3 e foi a menos frequente. Neste tipo de explicação, não é o juízo alheio que conta. Tratase do reconhecimento espiritual de uma dívida simbólica. Conforme Pan (M, 12;5) deixa claro, é o caráter desinteressado (McConnell, 1993) da ação da tia Ana que a torna digna de gratidão. A retribuição é uma forma de demonstrar essa gratidão. Deve-se retribuir, porque é bom. É bom, porque faz o outro se sentir feliz, proporcionando-se ao benfeitor a mesma satisfação sentida quando se recebeu o favor (Lap, F, 12;3). Como disse Comte-Sponville (2007), retribuição não é troca de favores, mas "o amor quer alegrar a quem lhe dá alegria” (p. 148). Além disso, a retribuição faz bem para a própria pessoa que retribui: "Não é que ele tenha que retribuir a boa ação porque ele é obrigado, mas pra ele ficar bem assim, mentalmente (...)" (Jur, M, 12;8). E o que seria esse "ficar bem assim, mentalmente" senão essa necessidade de coerência interna que garante a conservação dos valores independentemente das pressões externas (Piaget, 1954; 1965/1977), a qual caracteriza a autonomia moral?

Esse dever/querer retribuir que acompanha a alegria de ter recebido um favor gera prazer, bem-estar, e diferencia-se, assim, da obrigação imposta socialmente, que pode constranger e causar mal-estar. Outra diferença que se pode assinalar: se a retribuição é vivenciada como um bem moral, retribuir é um fim em si mesmo - deve-se retribuir porque é bom; se a retribuição é concebida como uma obrigação para atender a uma exigência social, retribuir é um meio para atingir um fim - deve-se retribuir para evitar o juízo alheio negativo. $\mathrm{O}$ fato de que a retribuição como bem moral apareceu em apenas 30\% dos participantes do Grupo 3 reforça a ideia de que seria expressão de uma consciência moral autônoma, a qual se constitui por volta dos 11-12 anos, em média. Da mesma forma, pode-se entender o pequeno número desse tipo de explicação, mesmo entre as crianças mais velhas. A formação da consciência moral autônoma é uma possibilidade da espécie humana, mas depende das interações vivenciadas no meio social (Piaget, 1972/1988).

Em síntese, os resultados indicam a existência de uma evolução na forma como as crianças concebem a obrigação de retribuir a um benfeitor prévio: (a) todas as crianças de 5-6 anos enfocaram as consequências - materiais ou psicológicas - para o benfeitor; (b) esse tipo de justificativa diminui com a idade; (c) a retribuição sentida como obrigatória para evitar o juízo alheio negativo foi a explicação mais encontrada entre as crianças de 7 anos ou mais; (d) a retribuição como um bem moral apareceu apenas em 30\% das crianças de 11-12 anos.
Todavia, nem todas as crianças concebem a retribuição como uma obrigação. Um resultado interessante deste estudo é justamente a constatação de que, para algumas crianças, o beneficiário pode ou não ajudar seu benfeitor e isso depende apenas de uma decisão pessoal. De certa forma, esse resultado já era esperado, pois se sabe que nem todas as pessoas acreditam que a retribuição a um benfeitor prévio é um dever (McConnell, 1993).

O menor número de respostas desse tipo não possibilitou o delineamento de subcategorias de análise para as justificativas apresentadas pelos participantes. No entanto, é possível perceber que há diferenças entre as respostas das crianças dos Grupos 1 e 2 e daquela do Grupo 3. Por exemplo, para Lab (F, 5;4) e Meb $(\mathrm{M}, 7 ; 11)$ a retribuição não é obrigatória, porque não há qualquer tipo de consequência ou punição, caso o beneficiário não ajude seu benfeitor. Para Ces (F, 12;4), porém, a retribuição não pode ser uma obrigação (no sentido de uma exigência social), pois o beneficiário precisa querer retribuir, ou seja, a retribuição só faz sentido se for um bem moral para aquele que retribui.

\section{Considerações finais}

Autores de diferentes disciplinas que analisaram e buscaram explicar a gratidão (Baumgarten-Tramer, 1938; Bonnie \& De Waal, 2004; Komter, 2004; McConnell, 1993; Piaget, 1965/1977) chamaram a atenção para o fato de que a alegria sentida pelo benefício recebido é acompanhada por uma dívida simbólica do beneficiário em relação ao benfeitor. Essa dívida geraria uma obrigação de retribuir o favor. Embora pareça existir um consenso na literatura de que gratidão e obrigação não são sinônimas, as diferenças entre uma e outra não estão claras. Neste artigo, argumentou-se que o estudo de como as crianças compreendem a retribuição de um benefício poderia contribuir para esclarecer essas diferenças.

Assim, investigou-se se, para crianças de diferentes grupos etários, haveria obrigação de retribuir um favor, enfocando-se os tipos de justificativas apresentados pelos participantes do estudo. A análise das respostas das crianças baseou-se na diferença estabelecida por Piaget (1932/1992) entre as duas formas de obrigação que se encontram no desenvolvimento moral do ser humano: obediência e sentimento de dever ou obrigação moral.

Os resultados indicaram que, para a maioria das crianças, se deve ajudar um benfeitor prévio, embora para algumas a retribuição não constitua uma obrigação. Explicar por que a retribuição é, para alguns, uma obrigação, enquanto, para outros, um assunto da esfera pessoal está além dos limites e propósitos deste artigo. No entanto, a busca de tal explicação seria um instigante tema de pesquisa.

A análise das justificativas das crianças que acreditam que se deve ajudar a um benfeitor prévio indicou que existe um desenvolvimento na forma como as crianças entendem a retribuição: (a) todas as crianças de 5-6 anos deste estudo justificaram que se deve ajudar para se evitar um dano ao benfeitor; (b) a maioria das crianças disse que se deve retribuir para evitar um juízo alheio negativo (ser considerado ingrato, mal-educado, preguiçoso, etc.) e (c) a retribuição como bem moral apareceu apenas em 30\% das crianças de 11-12 anos. 
Essa análise também permitiu confirmar a ideia de que o estudo de como as crianças compreendem a retribuição de um favor poderia contribuir para esclarecer as diferenças entre obrigação e gratidão. A obrigação de retribuir, gerada pela dívida simbólica entre benfeitor e beneficiário, é fonte de bemestar, quando concebida como um bem moral. Se vista apenas como forma de evitar o juízo alheio negativo, a obrigação de retribuir pode ser constrangedora e ser fonte de mal-estar para o beneficiário.

Este estudo representa um primeiro passo, mas outras pesquisas precisam ser realizadas sobre a retribuição, no contexto da dívida simbólica presente na gratidão. Em primeiro lugar, é necessário ampliar a amostra, a fim de verificar se o padrão de desenvolvimento encontrado se manteria o mesmo ou, pelo contrário, se os resultados encontrados seriam restritos aos participantes deste estudo. Em segundo lugar, seria interessante propor às crianças outras situações. Por exemplo, uma história em que não apenas o beneficiário, mas também o benfeitor fosse uma criança. Esta pesquisa está atualmente em andamento.

Emmons e Shelton (2002) consideram a realização de estudos sobre a emergência da gratidão na criança uma "prioridade crítica" (p. 468), visto que seria possível desenvolver programas educativos que a promovessem. Segundo Froh (2010), a melhor maneira de fomentar a gratidão entre crianças seria organizar programas para ensiná-las a pensar sobre, por exemplo, os benefícios recebidos, a intenção do benfeitor, os custos de sua ação generosa. Acredita-se que as diferenças entre a retribuição como obrigação social e como bem moral devam ser consideradas no delineamento de tais programas. Quando se trata do ciclo dar-receber-retribuir (Godbout, 1997), é relevante não apenas o que se faz, mas também como se faz.

\section{Agradecimentos}

As autoras agradecem ao apoio financeiro do $\mathrm{CNPq}$ (Processo 401900-0); à Fundação de Amparo à Pesquisa do Estado do Rio Grande do Sul (FAPERGS), por meio de bolsa de Iniciação Científica à primeira autora; e ao Programa de Iniciação Científica CNPq/Universidade Federal do Rio Grande do Sul (PIBIC CNPq/UFRGS), por meio de bolsa de Iniciação Científica à terceira autora.

\section{Referências}

Anderson, N. H. (2005). How sharper than a serpent's tooth. Journal of Social and Clinical Psychology, 24(7), 1077-1080.

Bartlett, M. Y., \& DeSteno, D. (2006). Gratitude and prosocial behavior: helping when it costs you. Psychological Science, 17, 319-325.

Baumgarten-Tramer, F. (1938). "Gratefulness" in children and young people. Journal of Genetic Psychology, 53, 53-66.

Bonnie, K. E., \& De Waal, F. B. M. (2004). Primate social reciprocity and the origin of gratitude. In R. A. Emmons \& M. E. McCullough (Orgs.), The psychology of gratitude (pp. 213-229). New York: Oxford University Press.

Bono, G., Emmons, R. A., \& McCullough, M. E. (2004). Gratitude in practice and the practice of gratitude. In P. A. Linley \& S. Joseph (Orgs.), Positive psychology in practice (pp. 464-481). New York: Wiley.

Bono, G., \& Froh, J. J. (2009). Gratitude in school: benefits to students and schools. In R. Gilman, E. S. Huebner, \& M. Furlong (Orgs.), Handbook of positive psychology in schools (pp. 77-88). New York: Routledge.

Comte-Sponville, A. (2007). Pequeno tratado das grandes virtudes (E. Brandão, Trad.). São Paulo: Martins Fontes.

Delval, J. (2002). Introdução à prática do método clínico: descobrindo o pensamento das crianças (F. Murad, Trad.). Porto Alegre: Artmed.

De Waal, F. B. M. (2007). Eu, primata: porque somos como somos (L. T. Motta, Trad.). São Paulo: Companhia das Letras.

Emmons, R. A., \& Shelton, C. M. (2002). Gratitude and the science of positive psychology. In C. R. Snyder, \& S. J. Lopez (Orgs.), Handbook of positive psychology (pp. 459-471). London: Oxford University Press.

Freitas, L. B. L. (2002). Piaget e a consciência moral: um kantismo evolutivo? Psicologia: Reflexão e Crítica, 15(2), 303-308.

Freitas, L. B. L. (2003). A moral na obra de Jean Piaget: um projeto inacabado. São Paulo: Cortez.

Freitas, L. B. L., Silveira, P. G., \& Pieta, M. A. M. (2009a). Sentimento de gratidão em crianças de 5 a 12 anos. Psicologia em Estudo, 14(2), 243-250.

Freitas, L. B. L., Silveira, P. G., \& Pieta, M. A. M. (2009b). Um estudo sobre o desenvolvimento da gratidão na infância. Revista Interamericana de Psicologia, 43(1), 49-56.

Froh, J. J. (2010, abril). Teaching children how to think gratefully: unveiling a new gratitude intervention for youth. Comunicação apresentada em Conference on Human Development, New York City.

Froh, J. J., Kashdan, T. B., Ozimkowski, K. M., \& Miller, N. (2009). Who benefits the most from a gratitude intervention in children and adolescents? Examining positive affect as a moderator. The Journal of Positive Psychology, 4, 408-422.

Froh, J. J., Miller, D. N., \& Snyder, S. (2007). Gratitude in children and adolescents: development, assessment, and school-based intervention. School Psychology Forum, 2, 1-13.

Froh, J. J., Sefick, W. J., \& Emmons, R. A. (2008). Counting blessings in early adolescents: an experimental study of gratitude and subjective well-being. Journal of School Psychology, 46, 213-233.

Godbout, J. T. (1997). O espirito da dádiva (J. P. Cabrera, Trad.). Lisboa: Instituto Piaget.

Komter, A. E. (2004). Gratitude and gift exchange. In R. A. Emmons, \& M. E. McCullough (Orgs.), The psychology of gratitude (pp. 195-212). New York: Oxford University Press.

La Taille, Y. (1992). Desenvolvimento do juízo moral e afetividade na teoria de Jean Piaget. In Y. La Taille, M. K. Oliveira, \& H. Dantas (Orgs.), Piaget, Vygotsky e Wallon: teorias psicogenéticas em discussão (pp. 47-73). São Paulo: Summus.

La Taille, Y. (2006). Moral e ética: dimensões intelectuais e afetivas. Porto Alegre: Artmed.

McConnell, T. (1993). Gratitude. Philadelphia: Temple University Press.

McCullough, M. E., Kilpatrick, S. D., Emmons, R. A., \& Larson, D. B. (2001). Is gratitude a moral affect? Psychological Bulletin, 127(2), 249-266.

McCullough, M. E., Tsang, J., \& Emmons, R. A. (2004). Gratitude in intermediate affective terrain: links of grateful moods with individual differences and daily emotional experience. Journal of Personality and Social Psychology, 86, 295-309.

Miller, D. N. (2006). Cultivating an attitude of gratitude: thanksgiving thoughts for school psychologists. Communiqué, 35(3), 5-6.

Paludo, S., \& Koller, S. H. (2006). Gratidão em contextos de risco: uma relação possível? Psicodebate, 7, 55-66.

Piaget, J. (s.d.). A representação do mundo na criança (R. Fiúza, Trad.). Rio de Janeiro: Record. (Texto original publicado em 1926)

Piaget, J. (1954). Les relations entre l'affectivité et l'intelligence. Paris: Sorbonne.

Piaget, J. (1977). Études sociologiques (3 ${ }^{\mathrm{a}}$ ed.). Genève: Droz. (Texto original publicado em 1965)

Piaget, J. (1988). Où va l'éducation? Paris: Denoël/Gonthier. (Texto original publicado em 1972)

Piaget, J. (1992). Le jugement moral chez l'enfant ( $7^{\mathrm{a}}$ Ed.). Paris: PUF. (Texto 
original publicado em 1932)

Pieta, M. A., \& Freitas, L. B. L. (2009). Sobre a gratidão. Arquivos Brasileiros de Psicologia, 61(1), 100-108.

Queiroz, S. S., Ronchi, J. P., \& Tokumaru, R. S. (2009). Constituição das regras e o desenvolvimento moral na teoria de Piaget: uma reflexão kantiana. Psicologia: Reflexão e Crítica, 22(1), 69-75.

Rammozzi-Chiarottino, Z. (2007). Razão e sentimento: aspectos orgânicos e simbólicos. In L. E. L. R. Valle \& K. O. Pinto (Orgs.), Mente e corpo: integração multidisciplinar em neuropsicologia (pp. 47-56). Rio de Janeiro: Mak Editora.

Sheldon, K. M., \& Lyubomirsky, S. (2006). How to increase and sustain positive emotion: the effects of expressing gratitude and visualizing best possible selves. Journal of Positive Psychology, 1, 73-82.
Silk, J. B. (2005). The evolution of cooperation in primate groups. In H. Gintis, S. Bowles, R. Boyd, \& E. Fehr (Orgs.), Moral sentiments and material interests: the foundations of cooperation in economic life (pp. 43-73). Cambridge: MIT Press.

Simmel, G. (1950). The sociology of Georg Simmel. Glencoe: Free Press.

Watkins, P. C., Scheer, J., Ovnicek, M., \& Kolts, R. (2006). The debt of gratitude: dissociating gratitude and indebtedness. Cognition and Emotion, 20(2), 217-241.

Watkins, P. C., Woodward, K., Stone, T., \& Kolts, R. L. (2003). Gratitude and happiness: development of a measure of gratitude, and relationships with subjective wellbeing. Social Behavior and Personality, 31, 431-452.

Westermarck, E. (1928). L'origine et le développement des idées morales (R. Godet, Trad.). Paris: Payot. (Texto original publicado em 1908)

1. A palavra gratidão, derivada do latim, tem as seguintes origens: gratia, que significa favor, e gratus, que significa agradável. Em português, o adjetivo grato significa tanto agradecido, reconhecido, quanto agradável.

2. Grifos do autor.

3. Toda resposta ou a justificativa de um participante, citada literalmente, é seguida de: (a) um conjunto de letras, abreviatura de um nome fictício, para preservar a identidade do participante, (b) a letra $\mathrm{M}$ ou F para indicar o sexo do participante, masculino ou feminino respectivamente e (c) dois números separados por ponto-e-vírgula, os quais representam a idade do participante em anos e meses. Assim, "5;2" significa 5 anos e 2 meses de idade.

4. Nas citações de entrevista, ler "P" como pesquisador e "E" como entrevistado.

Fernanda Maria Palhares Castro, especialista em Microinformática pela Universidade Federal do Rio Grande do Sul (UFRGS), é estudante de graduação de Psicologia na mesma instituição. Endereço para correspondência: Laboratório de Psicologia e Epistemologia Genética, Instituto de Psicologia, UFRGS. Rua Ramiro Barcelos, 2600, sala 118; Porto Alegre/RS. CEP: 90.035-003. Fone/fax: (51) 3308-5314; Celular: (51) 8440-9797. E-mail: fer_palhares@terra.com.br

Paula Grazziotin Silveira Rava, mestre em Psicologia pela Pontifícia Universidade Católica do Rio Grande do Sul (PUC-RS), é doutoranda do Programa de Pós-Graduação em Psicologia na Universidade Federal do Rio Grande do Sul (UFRGS). E-mail: paulagraz@yahoo.com

Tatiana Buchabqui Hoefelmann, graduada em Psicologia pela Universidade Federal do Rio Grande do Sul (UFRGS).E-mail: tatihoef@gmail.com

Maria Adélia Minghelli Pieta, mestre em Psicologia pela Universidade Federal do Rio Grande do Sul (UFRGS), doutoranda do Programa de Pós-Graduação em Psicologia na mesma instituição. E-mail: mampieta@gmail.com

Lia Beatriz de Lucca Freitas, doutora em Psicologia pela Universidade de São Paulo (USP), Professor Associado II na Universidade Federal do Rio Grande do Sul (UFRGS). E-mail: lblf@ufrgs.br 